\title{
Expression and Localization of DDX3 in Prostate Cancer Progression and Metastasis
}

\author{
Jordan E. Vellky, ${ }^{* \dagger \ddagger}$ Emily A. Ricke, ${ }^{* \ddagger \S}$ Wei Huang, ${ }^{\ddagger \S \Phi}$ and William A. Ricke ${ }^{\star \ddagger \S}$
}

From the Departments of Urology* and Pathology and Laboratory Medicine ${ }^{\top}$ and the Cancer Biology Graduate Research Program, ${ }^{\dagger}$ School of Medicine and Public Health, the George M. O'Brien Research Center of Excellence, ${ }^{\ddagger}$ and the Carbone Cancer Center, ${ }^{\S}$ University of Wisconsin, Madison, Wisconsin

Accepted for publication

February 14, 2019.

Address correspondence to William A. Ricke, Ph.D., Department of Urology, 7107 Wisconsin Institute for Medical Research, University of Wisconsin, 1111 Highland Ave., Madison, WI 53705. E-mail: rickew@urology.wisc.edu.

\begin{abstract}
Survival rates decrease significantly when localized prostate cancer (CaP) becomes metastatic, emphasizing the need for improved targeted therapies. DDX3, an RNA helicase, has widespread functions in RNA regulation, in both the nucleus and cytoplasm. Although DDX3 has been implicated as a prognostic marker for many cancers, including primary $\mathrm{CaP}$, its expression, localization, and function in metastatic CaP have not been investigated. Analysis of metadata and cell line models found increased DDX3 expression in metastatic versus primary $\mathrm{CaP}$ and benign prostate. Quantification of DDX3 expression in 320 human prostate samples, representing different stages of $\mathrm{CaP}$ progression, revealed an increase in epithelial whole cell, cytoplasmic, and nuclear DDX3 in primary CaP compared with benign prostate. In metastatic tissues, cytoplasmic DDX3 remained highly expressed, whereas nuclear DDX3 significantly decreased compared with primary CaP, suggesting a potential role for cytoplasmic DDX3 in metastatic CaP. Genetic and pharmacologic loss of function for DDX3 in metastatic CaP produced a significant decrease in cell viability, proliferation, and motility but did not affect apoptosis. The data suggest that cytoplasmic DDX3 is highly expressed in metastatic CaP and that inhibition of DDX3 affects metastatic growth by decreasing proliferation and motility. These findings introduce a novel role for cytoplasmic DDX3 in CaP progression and provide a foundation for clinically targeting DDX3 in metastatic CaP. (Am J Pathol 2019, 189: 1256-1267; https://doi.org/10.1016/j.ajpath.2019.02.011)
\end{abstract}

Prostate cancer $(\mathrm{CaP})$ is the second most prevalent cancer diagnosed among men in the United States, with 164,690 new cases expected in 2018 , corresponding to $9.5 \%$ of all new cancer cases. ${ }^{1}$ Of these diagnoses, 29,430 men are expected to die of $\mathrm{CaP}$, equating to $4.8 \%$ of all cancerrelated deaths. ${ }^{1}$ Importantly, although the 5-year survival rate for localized and regional $\mathrm{CaP}$ is $>99 \%$, patients with distant metastases have only a 30\% 5-year survival rate. ${ }^{1}$ Treatment for metastatic $\mathrm{CaP}$ includes endocrine-based therapies, which despite initial success inevitably result in advanced disease progression. ${ }^{2,3}$ After endocrine therapy failure, taxane-based chemotherapy is prescribed to nonspecifically target dividing cells, which improves median survival for metastatic $\mathrm{CaP}$ by 2 to 3 months. ${ }^{3-5}$ Although advances in immunotherapies have improved survival times to approximately 4.5 months, identifying features of aggressive (metastatic) $\mathrm{CaP}$ is imperative to ascertain improved targeted therapies and patient survival.
DDX3 (DEAD-box helicase $3 \mathrm{X}$-linked) is an ATPdependent RNA helicase that is known to play a role in nearly all stages of RNA processing in both the nucleus and cytoplasm. In the nucleus, DDX3 has roles in transcription, splicing, and nuclear export. As a transcriptional regulator, DDX3 i) interacts with SP1 transcription factor to upregulate $p 21^{\text {wafl/cip } 1}$ and $K R A S$, ii) directly binds the interferon $\beta$ promoter to induce activation, and iii) regulates transcription of E-cadherin as both a repressor and an activator. $^{8-13}$ DDX3 has also been identified as a component of the spliceosome ${ }^{14,15}$ and interacts with the nuclear export proteins chromosomal maintenance 1 and transporter associated with antigen processing to assist in mRNA

Supported by NIH grants DK104310 (W.A.R.), CA009135 (J.E.V.), and CA014520 (University of Wisconsin Carbone Cancer Center, H.B.). J.E.V. is a trainee in the Cancer Biology Graduate Program at the University of Wisconsin-Madison.

Disclosures: None declared. 
nuclear export. ${ }^{16,17}$ These functions of nuclear DDX3 suggest it may be involved in context-dependent growth induction or suppression, immune response, motility, and/or invasion.

In the cytoplasm, DDX3 acts as a regulator of translation. Under normal conditions, DDX3 binds mRNA as part of the translation initiation complex with other components, including the poly(A)-binding protein and eukaryotic initiation factors $2 \mathrm{a}, 3$, and 4E/F. ${ }^{16,18-20}$ Here, DDX3 hydrolyzes ATP to resolve the secondary structure of target mRNA, allowing translation initiation. ${ }^{16,20,21}$ Alternatively, under stress conditions, such as heat shock, oxidative stress, ischemia, or viral infection, DDX3 localizes to ribonucleoprotein granules known as stress granules to transiently prevent translation of target mRNA. ${ }^{19,22,23}$ Identified targets of DDX3-mediated translational regulation include Ras family small GTPase 1 and cyclin-E1, suggesting that cytoplasmic DDX3 as a translational regulator may influence cell division and/or cell growth. ${ }^{24,25}$

DDX3 has recently been implicated as a prognostic marker in several cancer types. ${ }^{26}$ Nuclear DDX3 was identified as a negative prognostic factor in breast cancer and glioblastoma, whereas increased cytoplasmic DDX3 is considered a negative prognostic factor in breast, lung, gallbladder, head and neck, and skin cancers. ${ }^{26}$ Recently, increased DDX3 protein expression has been associated with triple negative breast cancer and advanced Gleason scores in primary CaP. ${ }^{11,27,28}$ RK33, a small molecule inhibitor specific to DDX3, has positive combinatorial therapeutic effects with radiotherapy in lung and primary $\mathrm{CaP}$, where co-treatment decreased proliferation and increased apoptosis. ${ }^{27,29}$ Given the correlation between DDX3 localization and primary $\mathrm{CaP}$ with high Gleason scores, it is expected that DDX3 localization and expression are also increased in $\mathrm{CaP}$ metastases, which has yet to be evaluated.

A better understanding of DDX3 in metastatic $\mathrm{CaP}$ could elucidate mechanisms of disease progression and provide a foundation for development of improved therapeutics. The various roles of DDX3, both nuclear and cytoplasmic, have been explored in a multitude of cancers; however, the role of DDX3 in metastatic $\mathrm{CaP}$ remains unstudied. Therefore, identifying the expression and localization of DDX3 in this context could provide insight into its function in advanced disease. Here, patient tissues and cell line models for $\mathrm{CaP}$ progression, as well as publicly available gene expression data, were used to investigate the expression, localization, and function of DDX3 in CaP metastases.

\section{Materials and Methods}

Meta-Analysis

Oncomine data were accessed online at https://www. oncomine.org (registration required). ${ }^{30}$ Data sets were analyzed for $\mathrm{CaP}$ using the cancer versus normal analysis for gene $D D X 3 X .^{30}$ The reporter accession numbers for each data set are as follows: 212514_x_at, ${ }^{31}$ IMAGE: 745188, ${ }^{32}$ A_24_P126060, ${ }^{33} 39744 \_$at, ${ }^{34}$ and 826_at. ${ }^{35}$ Gene Expression Omnibus (GEO, https://www.ncbi.nlm.nih.gov/geo) data set GDS1439 was analyzed with the GEO2R analysis tool version 2013 for gene $D D X 3 X$ (1558120_at). ${ }^{36}$

\section{Patient Samples and Immunohistochemistry}

The CaP progression tissue microarray was created by a board-certified pathologist (W.H.) and contains 336 cores of $0.6 \mathrm{~mm}$ from 168 patients (two cores per patient) cut into in $5-\mu \mathrm{m}$ sections. This array includes 96 cores (48 patients) of benign prostatic tissue (BPT), 50 cores (25 patients) of high-grade prostatic intraepithelial neoplasia (HGPIN), 146 cores (73 patients) of $\mathrm{CaP}$, and 44 cores (22 patients) of metastatic tissue (METS). ${ }^{37}$ Diagnosis of cores was determined by histologic findings that represented most of the core $(<5 \%$ intermixed gland diagnoses) and confirmed by the board-certified pathologist (W.H.) at 10 -section intervals. Cores that contained $>5 \%$ intermixed glands, that contained $<100$ total cells, or were significantly damaged during processing were excluded from the analysis, resulting in total sample sizes of: 46 patients with BPT, 24 patients with HGPIN, 71 patients with $\mathrm{CaP}$, and 19 patients with METS. Immunohistochemical analysis using a commercially available antibody against DDX3 (1:250 dilution, catalog number A300-474A; Bethyl Laboratories Inc, Montgomery, TX) was detected using diaminobenzidine chromogen (catalog number 8059; Cell Signaling Technology, Danvers, MA). Mayer's hematoxylin was used as the nuclear counterstain.

\section{Automated Image Acquisition and Analysis}

IHC quantification was performed as previously described. ${ }^{37,38}$ Briefly, the progression tissue microarray slide was scanned and imaged at $\times 20$ magnification using a Vectra2 quantitative pathology imaging system. inForm Cell Analysis software version 2.1 (PerkinElmer, Waltham, MA) was used to create spectral libraries of diaminobenzidine and hematoxylin staining, which allows for separation of the two stains. With the use of the Tissue Finder function of inForm software version 2.1 (PerkinElmer), tissue types (stroma, epithelia) and cell compartments (nuclear, cytoplasmic) were segmented and quantified. ${ }^{37}$ The mean optical density (OD) was calculated for each core, and the two cores from the same patient were averaged to create a single mean OD value for each patient. For each core, epithelial mean OD was normalized to stromal mean OD to control for background staining. Statistical change was analyzed using a one-way analysis of variance with Tukey's multicomparison test. 
Table 1 DDX3 Expression Increases in Prostate Cancer (CaP) Progression

\begin{tabular}{llll}
\hline Data set & $P$ value & Fold change & Comparison \\
\hline Wallace et $\mathrm{al}^{31}$ & 0.000184 & 2.154 & Primary CaP versus healthy \\
Tomlins et $\mathrm{al}^{33}$ & 0.046 & 1.302 & Primary CaP versus healthy \\
Grasso et $\mathrm{al}^{32}$ & 0.054 & 1.106 & Primary CaP versus healthy \\
Singh et $\mathrm{al}^{34}$ & 0.072 & 1.565 & Primary CaP versus healthy \\
LaTulippe et $\mathrm{al}^{35}$ & 0.164 & 1.309 & Primary CaP versus healthy \\
Varambally et $\mathrm{al}^{36}$ & 0.023 & 2.216 & Metastatic versus primary CaP \\
\hline
\end{tabular}

\section{Cell Culture}

RWPE-1, PC3, and DU145 cells were obtained from ATCC (Manassas, VA). BPH1 and BHPrE cells were generously provided by Dr. Simon Hayward at Northshore University Health Systems. LNCaP, C42, and C42B cells were obtained from collaborators at University of Wisconsin, Madison. Benign $\mathrm{CaP}(\mathrm{BCaP})$ cell lines were created in the Ricke laboratory as described previously. ${ }^{39-41}$ All cell lines were maintained in RPMI 1640 medium and $2.05 \mathrm{mmol} / \mathrm{L}$ L-glutamine media (Hyclone, Logan, UT) supplemented with 5\% fetal bovine serum (Hyclone), 2.5\% HEPES (Hyclone), 1\% penicillin/streptomycin (Hyclone), and $0.2 \%$ normacin (Invivogen, San Diego, CA) and routinely passaged.

\section{Protein Expression}

Cells were seeded in tissue culture grade petri dishes and grown to confluence. Western blot protocol was performed as previously described, ${ }^{42}$ using BioRad precast gels and nitrocellulose membrane transfer packages (BioRad, Hercules, CA). Antibodies specific to DDX3 (catalog number A300-474A, Bethyl Laboratories Inc) and $\alpha$-tubulin ( $\alpha$-tub) (catalog number 2125; Cell Signaling Technology) were diluted in $5 \%$ bovine serum albumin/Tris-buffered saline/ Tween-20 (DDX3 1:2000; $\boldsymbol{\alpha}$-tub 1:1000) and incubated overnight at $4{ }^{\circ} \mathrm{C}$. Species-specific horseradish peroxidase-conjugated secondary antibodies (Bethyl Laboratories Inc) were incubated at room temperature for 1 hour and visualized using chemiluminescent substrate DURA (Thermo Fisher Scientific, Waltham, MA). Band intensity was quantified with ImageJ version $1.49 \mathrm{v}^{43}$ (NIH, Bethesda, MD; http://imagej.nih.gov/ij).and normalized to total protein, which was quantified using stain-free imaging as previously described. ${ }^{43} \alpha$-Tub was used as a visual loading control.

\section{Cell Viability Assay}

$\mathrm{BCaP}^{\mathrm{M} 1}$ or $\mathrm{C} 42$ cells were seeded at a density of 30,000 cells per well. After adherence, DDX3 inhibition was achieved by transfection with $25 \mathrm{nmol} / \mathrm{L}$ siRNA targeting DDX3 or treatment with $2 \mu \mathrm{M}$ RK33. SMARTpool ONTARGETplus Human $D D X 3 X$ siRNA [siRNA targeting
DDX3 (siDDX3)] was acquired from Dharmacon (catalog number L-006874-02-0005), with the associated siRNA nontargeting scramble control (siSCBL) (catalog number D001810-10-05). Cells were transiently transfected with 25 nmol/L siDDX3 or siSCBL control using the Mirus Bio TransIT X2 Dynamic Delivery System (catalog number MIR 6005), according to Mirus' protocol. After 12 hours, transfection reagent was removed, and cells continued to grow in RPMI 1640 medium for $0,1,2$, or 4 days after transfection. Alternatively, DDX3 was inhibited pharmacologically by treatment with $2 \mu \mathrm{M}$ RK33 (catalog number 1070773-09-9; SelleckChem, Houston, TX), diluted in dimethyl sulfoxide (DMSO). RK33, or DMSO control, and added to media on day 0 , and cells were counted on days 0 , 2, 4, and 6 after treatment. Cell viability was assessed at each time point by staining with trypan blue and counted using a TC-20 automated cell counter (BioRad, Hercules, CA).

\section{Immunofluorescence}

Immunofluorescence was performed according to Abcam's protocol (Abcam, Cambridge, UK). Briefly, cells were fixed, permeabilized, and then incubated with primary antibodies DDX3 (diluted 1:250; catalog number A300-474A; Bethyl Laboratories Inc), Ki-67 (diluted 1:200; catalog number ab15580; Abcam), or cleaved caspase (cCASP)-3 (diluted 1:250; catalog number 9661; Cell Signaling Technology), followed by anti-rabbit conjugated to AlexaFluor 488 (catalog number A-21206; Thermo Fisher Scientific). For the gain-of-function experiments, $\mathrm{BCaP}^{\mathrm{M} 1}$ or $\mathrm{C} 42$ cells were grown on coverslips and treated as described above with either siRNA for 12 hours or RK33 for 48 hours before fixation. All cells were counterstained with DAPI nuclear stain. Images were taken at $\times 20$ magnification. Fluorescence intensity (measured in arbitrary units) and percent positivity were calculated using ImageJ version $1.49 \mathrm{v} .{ }^{44}$

\section{Motility Assay}

$\mathrm{BCaP}^{\mathrm{M} 1}$ or $\mathrm{C} 42$ cells were plated at a seeding density of 50,000 cells per well. After adherence, cells were treated with a DDX3 inhibitor or control. DDX3 was inhibited as described above by transfection with $25 \mathrm{nmol} / \mathrm{L}$ siRNA targeting DDX3 or treatment with $2 \mu \mathrm{M}$ RK33. A total of 
A
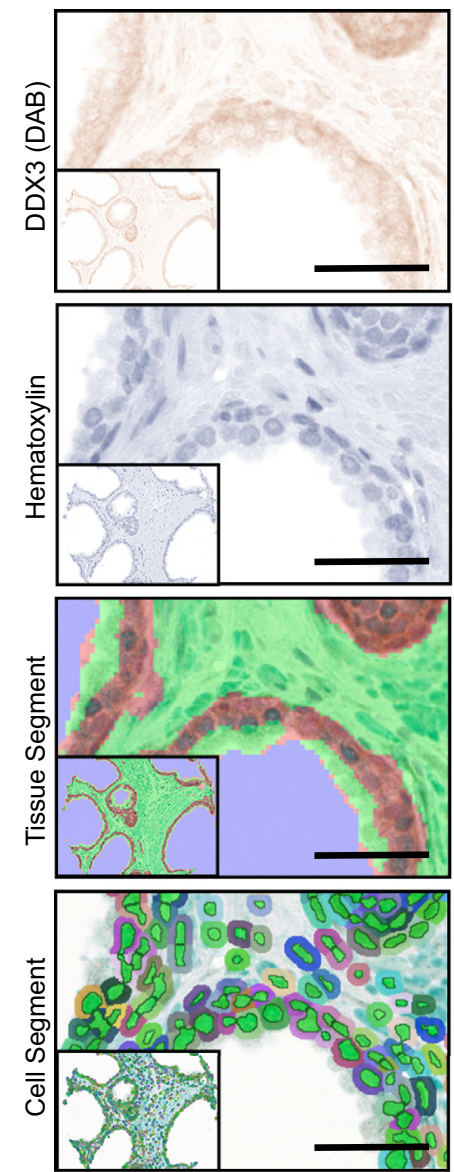

B

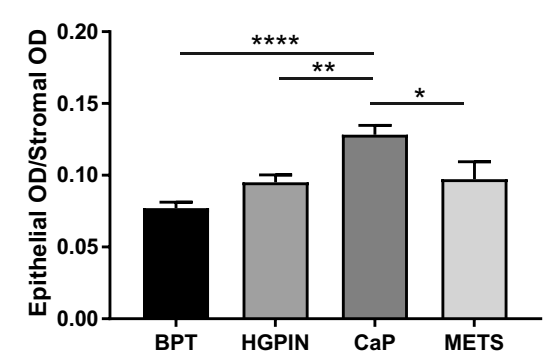

HGPIN
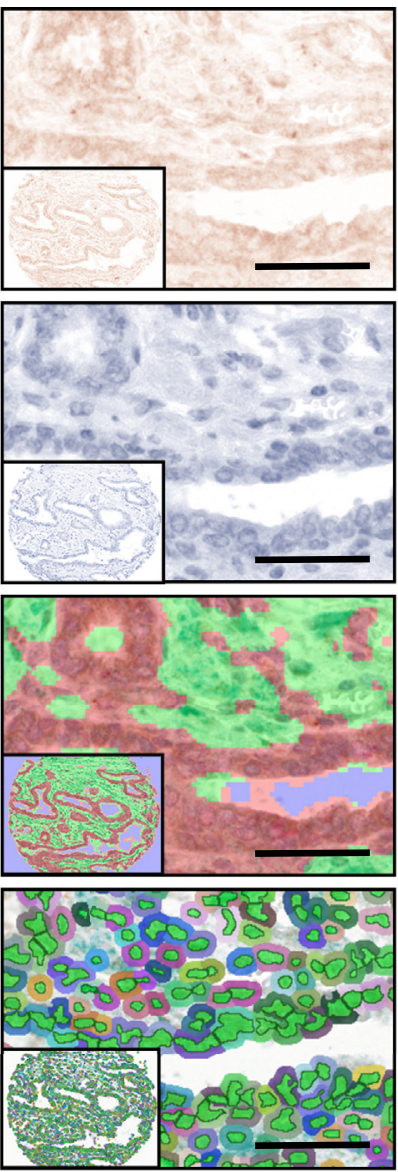

$\mathrm{CaP}$
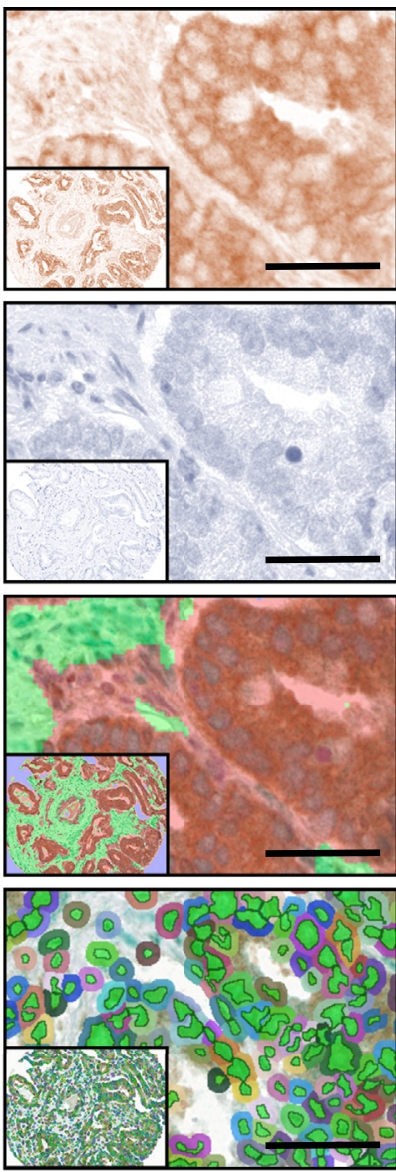

Nuclear

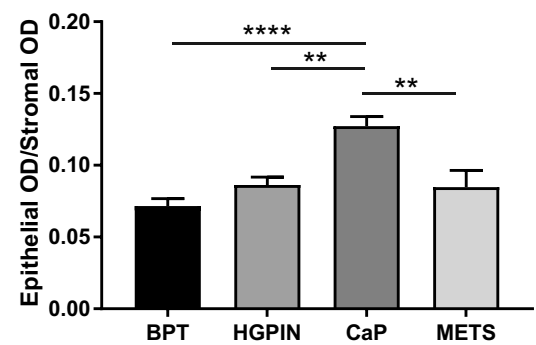

METS
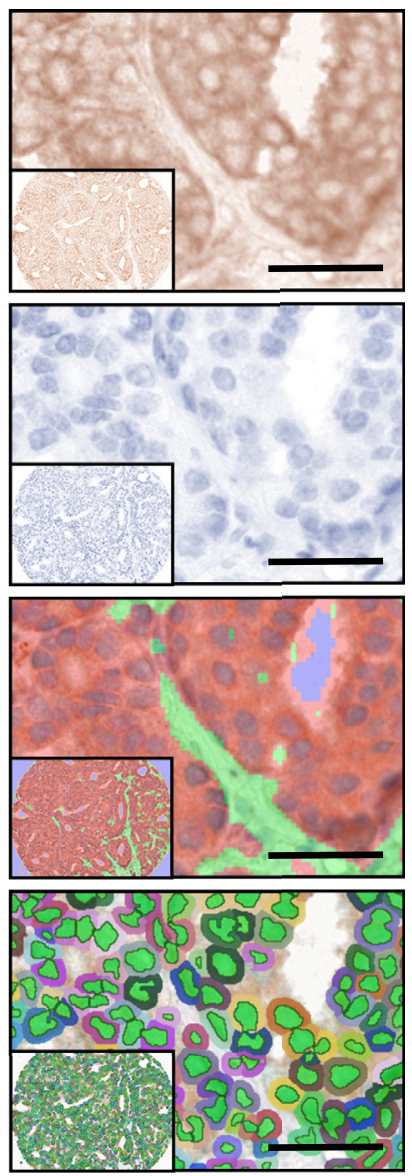

Cytoplasmic

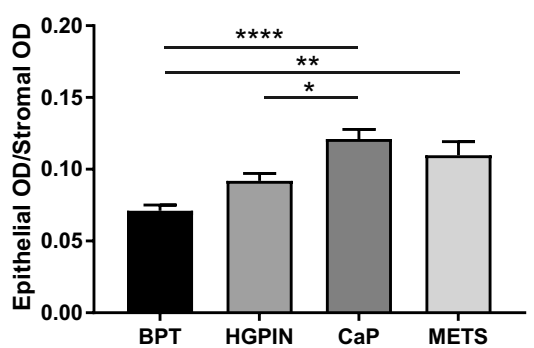

Figure 1 Cytoplasmic DDX3 is highly expressed in metastatic prostate cancer (CaP) tissue. A: DDX3 expression (brown) was analyzed in a CaP progression tissue microarray (pTMA) that contained cores from patients with benign prostate tissue (BPT; $n=46)$, high-grade prostatic intraepithelial neoplasia (HGPIN; $n=24)$, CaP $(n=71)$, and metastatic tissue (METS; $n=19)$ (first row). Hematoxylin (blue) was used to counterstain nuclei (second row). Machine learning software (inForm Cell Analysis software version 2.1; PerkinElmer, Waltham, MA) was trained to segment prostate epithelia (red) versus stroma (green) (third row). Cell segmentation analysis distinguished nuclear (green) and cytoplasmic (multicolored) staining (fourth row). B: Quantification of DDX3 expression in the pTMA shows significantly increased mean optical density (OD) in all cell compartments (whole cell, nuclear, cytoplasmic) for CaP versus BPT and CaP versus HGPIN. DDX3 expression was increased in METS versus BPT in the cytoplasm only. DDX3 expression was decreased in METS versus CaP in whole cell and nuclear but not significantly different in the cytoplasm. Mean OD in the epithelia was

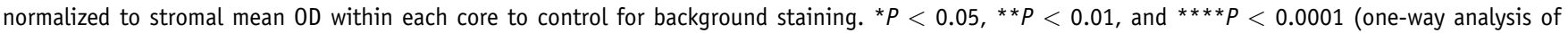
variance with Tukey multicomparison test). Scale bars $=25 \mu \mathrm{m}$. Original magnification, $\times 20$ (insets).

48 hours after treatment, a $20-\mu \mathrm{L}$ pipette tip was used to create a scratch through the cell monolayer in the center of each well, as previously described. ${ }^{40}$ Images were taken at $0,6,12$, and 24 hours, and the area of the scratch was quantified with ImageJ version $1.49 \mathrm{v}$. Percentage of scratch closure was calculated by dividing the area of the scratch at each time point by the area of the scratch at 0 hour for each condition and subtracting the resulting percentage from 100. Statistics reflect 3 biological replicates for each treatment. 
A
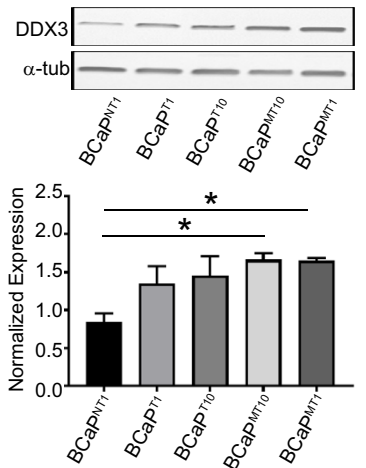

B
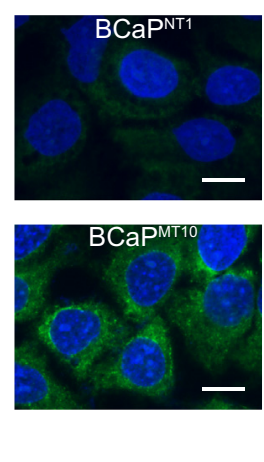
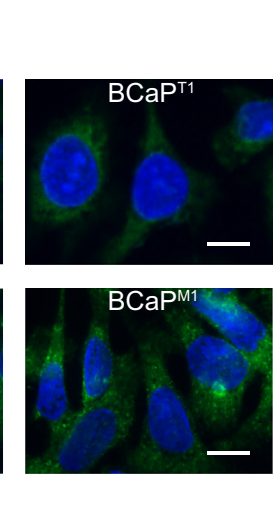

C
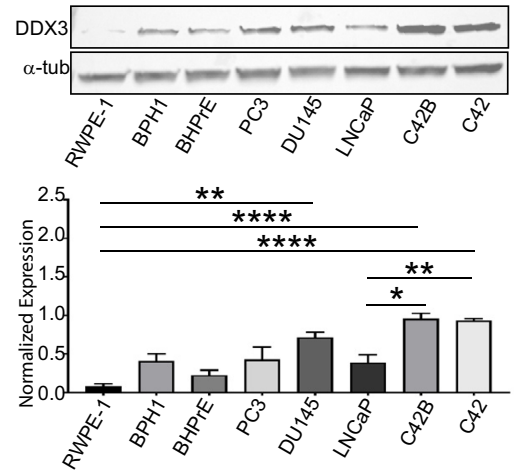

D
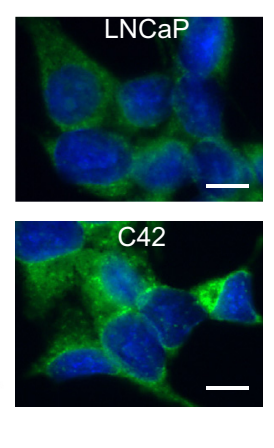

Figure 2 Cytoplasmic DDX3 expression is highly expressed in cell line models of prostate cancer (CaP) metastasis. A: Quantification of DDX3 expression by Western blot shows a significant increase in the metastatic lines $\mathrm{BCaP}^{\mathrm{MT} 10}$ and $\mathrm{BCaP} \mathrm{P}^{\mathrm{M} 1}$ compared with nontumorigenic line $\mathrm{BCaP}^{\mathrm{NT} 1}$. Bands were quantified by densitometry in ImageJ version $1.49 \mathrm{v}$. and normalized to total protein. $\alpha$-Tubulin ( $\alpha$-tub) was used as a visual loading control. B: Localization of DDX3 in BCaP cell lines shows high cytoplasmic DDX3 expression (green) in metastatic cell lines BCaP ${ }^{M T 10}$ and $\mathrm{BCaP}^{\mathrm{M1}}$ compared with nontumorigenic cell line BCaP ${ }^{\mathrm{NT1}}$ and early primary tumor cell line $\mathrm{BCaP}^{\mathrm{T} 1}$. There is minimal nuclear staining. DAPI (blue) was used as the nuclear counterstain. C: Quantification of DDX3 expression in a panel of benign (RWPE-1, BPH1, BHPrE) and CaP (PC3, DU145, LNCaP, C42B, C42) cell lines shows increased DDX3 in DU145, C42B, and C42 compared with nontumorigenic prostate RWPE-1 cell lines. DDX3 expression is significantly increased in C42B and C42 compared with LNCaP. Bands were quantified by densitometry in ImageJ version $1.49 \mathrm{v}$ and normalized to total protein. $\alpha$-Tub was used as a visual loading control. D: Localization of DDX3 in LNCaP parental and derivative (C42) cell lines shows that DDX3 (green) primarily localizes to the cytoplasm in both models, with higher expression in C42 (bottom panel) compared with LNCaP (top panel). DAPI (blue) was used as the nuclear counterstain. $n=3$ Western blots $\left(\mathbf{A}\right.$ and $\mathbf{C}$ ). ${ }^{*} P<0.05,{ }^{*} P<0.01$, and $* * * * P<0.0001$ (Welch $t$-test). Scale bars $=5 \mu \mathrm{m}$. Original magnification, $\times 20$.

\section{Statistical Analysis}

Data reflect the mean of samples within each category or treatment, and error bars reported indicate SEM. GraphPad/ Prism software version 7.05 (GraphPad Software, Inc., La Jolla, CA) was used for all statistical analysis, with a Welch $t$-test for 3 replicates or a one-way analysis of variance with Tukey's test for multicomparison statistics. $P \leq 0.05$ was considered to be statistically significant.

\section{Results}

\section{DDX3 Expression Increases in Meta-Analysis of CaP Progression}

The expression of DDX3 in advanced/metastatic CaP has not been investigated. To assess DDX3 expression in $\mathrm{CaP}$ progression, data-mining platform Oncomine and other publicly available data sets were used. Oncomine data revealed a significant increase in DDX3 expression in primary $\mathrm{CaP}$ versus healthy samples in the Wallace et $\mathrm{al}^{31}$ and Tomlins et $\mathrm{al}^{33}$ data sets $(P=0.0002$ and $P=0.046$, respectively $)^{30}$ (Table 1). However, other data sets found a trend toward significance $(P=0.054$ in the study by Grasso et $\mathrm{al}^{32}$ and $P=0.072$ in the study by Singh et $\mathrm{al}^{34}$ ) or no significant change $(P=0.164$ in the study by LaTulippe et $\mathrm{al}^{35}$ ) (Table 1). ${ }^{30}$ To assess the expression of DDX3 (associated gene noted $D D X 3 X$ ) in primary versus metastatic $\mathrm{CaP}$, the publicly available data set GDS1439 was used. ${ }^{36}$ Here, DDX3 was significantly increased in metastatic $\mathrm{CaP}$ samples $(n=6)$ versus primary $\mathrm{CaP}(n=7)$
$(P=0.023)$ (Table 1$)$. These data suggest DDX3 gene expression can be high in metastatic $\mathrm{CaP}$.

\section{Cytoplasmic DDX3 Is Highly Expressed in Metastatic CaP Tissue}

DDX3 is a multifunctional protein that plays a role in nuclear and cytoplasmic RNA processing. Therefore, analyzing the relative expression and localization of DDX3 in $\mathrm{CaP}$ progression may provide insight into its functional significance. DDX3 staining was detected in a human prostate tissue microarray that contained cores histologically categorized as BPT $(n=46)$, HGPIN $(n=24), \mathrm{CaP}(n=$ $71)$, or METS $(n=19)$ (Figure 1A). ${ }^{37}$ inForm software version 2.1 was trained to segment prostate epithelia versus stroma (Figure 1A). ${ }^{45,46}$ The mean OD of the epithelial staining was normalized to background by dividing it by the mean OD of the stroma for each core. The staining was then quantified by cell compartment (nuclear, cytoplasmic, whole cell) and compared between disease stages (Figure 1A). Both whole cell and nuclear DDX3 expression was significantly increased in $\mathrm{CaP}$ compared with $\mathrm{BPT}(P<0.0001)$ and HGPIN $(P=0.021$ for whole cell and $P=0.001$ for nuclear) but significantly decreased in METS compared with $\mathrm{CaP}(P=0.035$ for whole cell and $P=0.002$ for nuclear) (Figure 1B). There was no significant change in whole cell or nuclear DDX3 expression between BPT and METS (whole cell $P=0.143$ and nuclear $P=0.713$ ). Interestingly, cytoplasmic DDX3 was significantly increased in $\mathrm{CaP}$ versus BPT $(P<0.0001)$ and $\mathrm{CaP}$ versus HGPIN $(P=0.021)$ and remained significantly increased in METS versus BPT $(P=0.005)$ (Figure $1 \mathrm{~B})$. No significant 

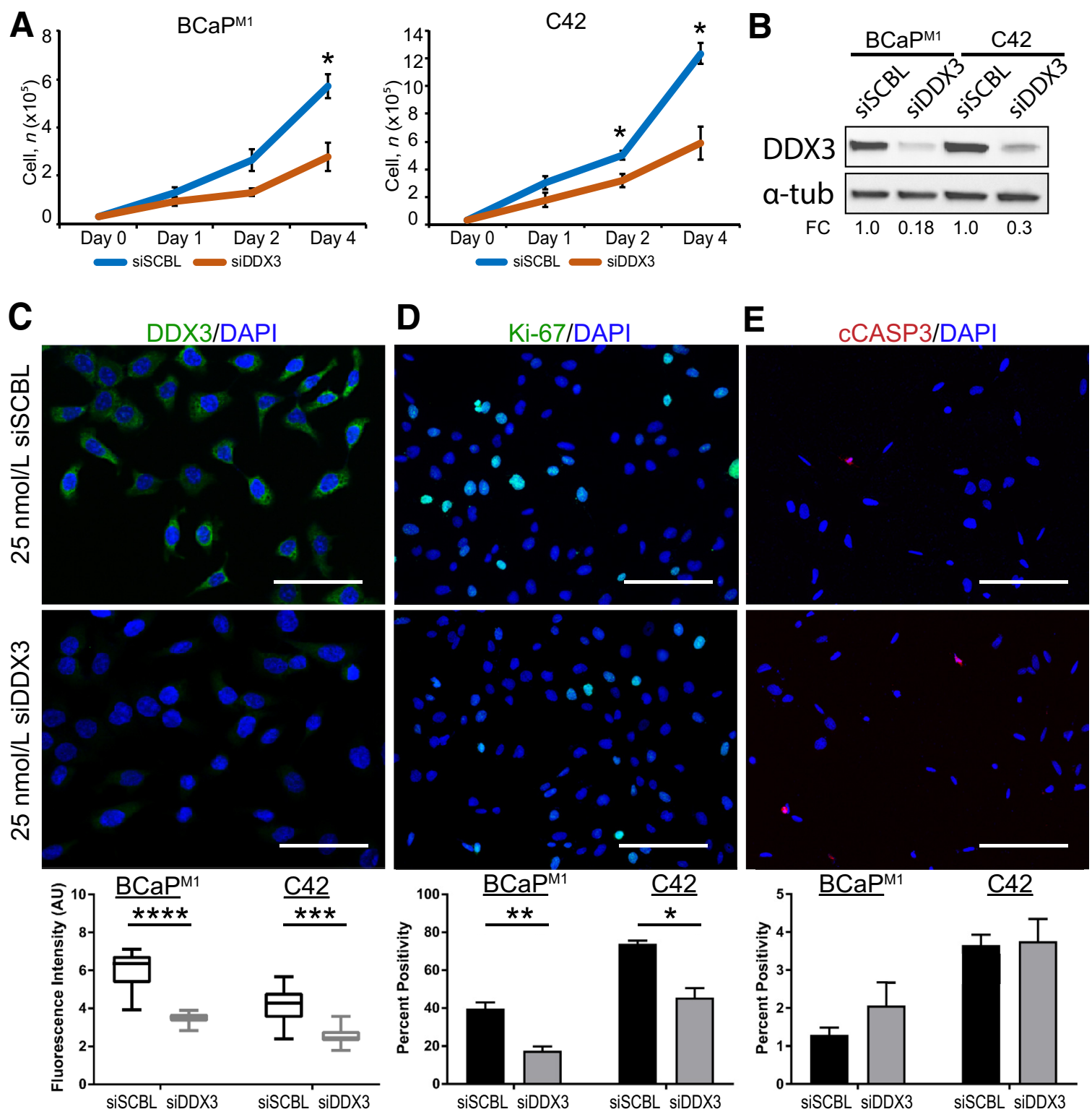

Figure 3 Genetic knockdown (KD) of DDX3 decreases proliferation in prostate cancer (CaP) metastasis models. A: Cell viability is significantly decreased with siRNA DDX3 (siDDX3) KD compared with control siRNA nontargeting scramble control (siSCBL) for the metastatic cell lines BCaP ${ }^{M 1}$ and C42. Cells were transiently transfected at day 0 with $25 \mathrm{nmol} / \mathrm{L}$ siDDX3 or siSCBL and counted using trypan blue at days 1,2 , and 4 after transfection. In $\mathrm{BCaP}{ }^{\mathrm{M} 1}$, there is no significant change in cell number between DDX3 KD and control at days 1 or 2 but a significant decrease with DDX3 KD at day 4. In C42, there is no significant difference in cell number at day 1 but a significant decrease with DDX3 KD at days 2 and 4. B: Western blot analysis shows a decrease of DDX3 protein with DDX3 KD by siRNA in both $\mathrm{BCaP}^{\mathrm{M} 1}$ and $\mathrm{C} 42$ cells. Expression of DDX3 was normalized to total protein, and $\alpha$-tubulin ( $\alpha$-tub) was used as a visual loading control. Densitometry was quantified in ImageJ version $1.49 \mathrm{v}$ and represented as fold change $(\mathrm{FC})$ over control. In $\mathrm{BCaP} \mathrm{P}^{\mathrm{M} 1} \mathrm{KD}$ cells, DDX3 expression decreases to 0.18 -fold compared with scramble control. In C42 KD cells, DDX3 expression decreases to 0.3-fold compared with scramble control. C: DDX3 protein expression (green) is significantly decreased in siDDX3-transfected cells compared with siSCBL (representative images shown for BCaP11; images for C42 not shown). DAPI nuclear stain is shown in blue. Fluorescence intensity was quantified in arbitrary units (AU) using ImageJ . D: Staining with the proliferation marker Ki-67 (green) shows a statistically significant reduction in Ki-67 positivity in siDDX3-transfected cells compared with siSCBL (representative images shown for $\mathrm{BCaP}^{\mathrm{M} 1}$;images for $\mathrm{C} 42$ not shown). DAPI nuclear stain is shown in blue. Percent positivity was calculated in ImageJ version $1.49 \mathrm{v}$. E: Staining with apoptosis marker cleaved caspase (cCASP)-3 (red) does not show a statistically significant difference in positivity between siDDX3 and siSCBL-transfected cells (representative images shown for $\mathrm{BCaP}^{\mathrm{M1}}$; images not shown for C42). DAPI nuclear stain is shown in blue. Percent positivity was calculated in ImageJ. $n=3$. ${ }^{*} P<0.05,{ }^{*} P<0.01,{ }^{* * *} P<0.001$, and ${ }^{* * * *} P<0.0001$ versus siDDX3 treatment (Welch $t$-test). Scale bars: $25 \mu \mathrm{m}$ (C); $50 \mu \mathrm{m}$ (D and E).

difference was found in cytoplasmic DDX3 in $\mathrm{CaP}$ versus METS $(P=0.728)$ (Figure 1B). Taken together, these data indicate that cytoplasmic, not nuclear, DDX3 is highly expressed in $\mathrm{CaP}$ metastases, and investigation of the role of DDX3 in the cytoplasm of these cells may be valuable.

\section{Cytoplasmic DDX3 Expression Is Highly Expressed in Cell Line Models of CaP Metastasis}

To address the role of DDX3 in the cytoplasm of metastatic $\mathrm{CaP}$ cells, both novel and established cell line models of 

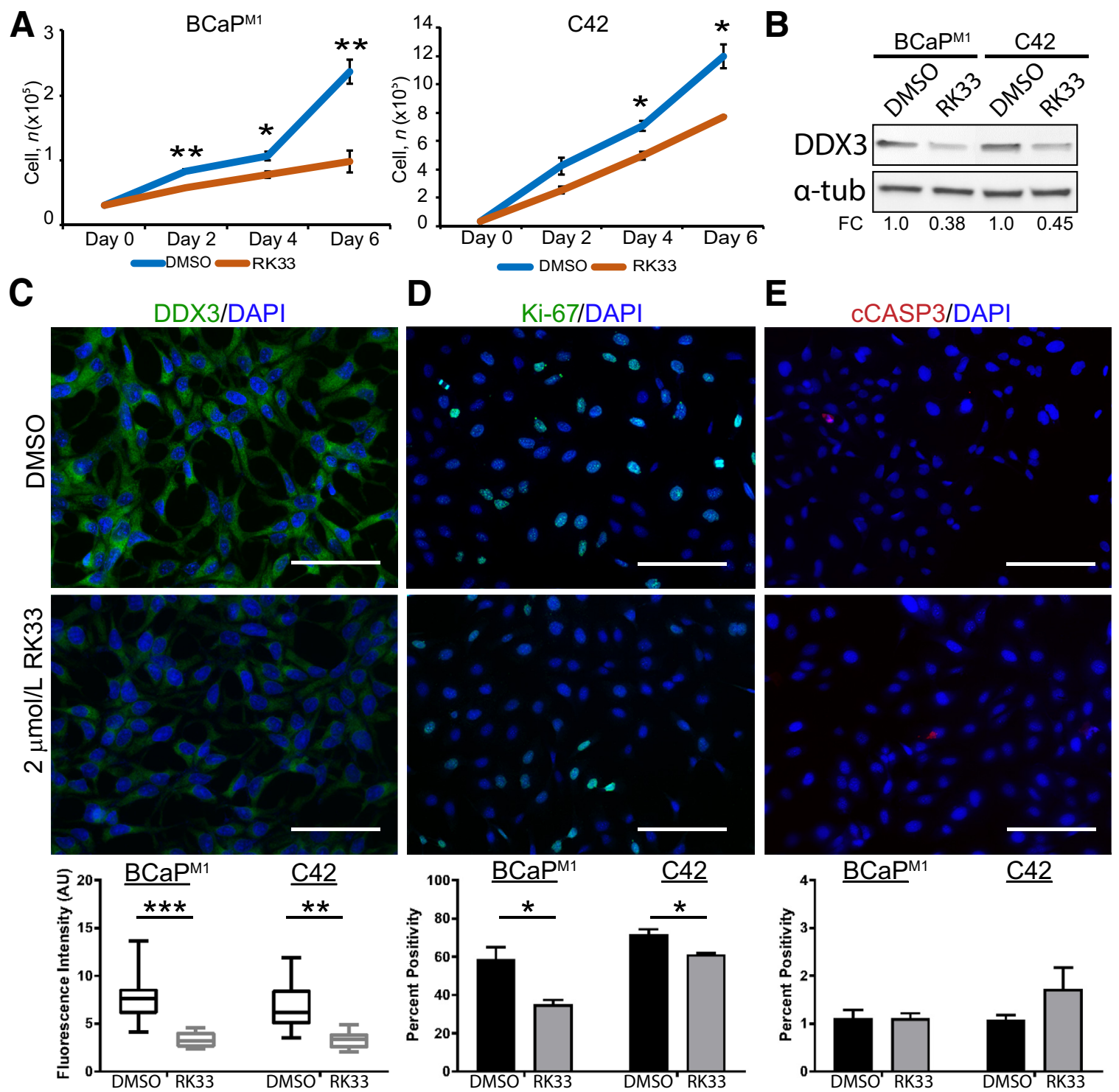

Figure 4 Pharmacologic inhibition of DDX3 decreases proliferation in prostate cancer (CaP) metastasis models. A: Cell viability is significantly decreased with $2 \mu$ M RK33 treatment compared with dimethyl sulfoxide (DMSO) control. BCaPM1 and C42 cells were treated at day 0 with $2 \mu$ M RK33 or DMSO control and counted using trypan blue at days 2, 4, and 6 after treatment. In $\mathrm{BCaP}^{\mathrm{M} 1}$, there is a significant decrease in cell viability of RK33-treated cells compared with DMS0 control at days 2, 4, and 6. In C42, cell number was significantly decreased with RK33-treatment at days 4 and 6 but not day 2. B: Western blot analysis shows a decrease of DDX3 protein with DDX3 inhibited by RK33 in both BCaPM1 and C42 cells. Expression of DDX3 was normalized to total protein, and $\alpha$ tubulin ( $\alpha$-tub) was used as a visual loading control. Densitometry was quantified in ImageJ version $1.49 \mathrm{v}$ and represented as fold change (FC) over control. In $\mathrm{BCaP}^{\mathrm{M1}}$ cells treated with RK33, DDX3 expression decreased to 0.38-fold compared with DMSO control. In C42 cells treated with RK33, DDX3 expression decreased to 0.45 -fold compared with DMSO control. C: DDX3 protein expression (green) is significantly decreased in RK33-treated cells compared with DMSO control (representative images are shown for $\mathrm{BCaP}^{\mathrm{M} 1}$;images for $\mathrm{C} 42$ are not shown). DAPI nuclear stain is shown in blue. Fluorescence intensity was quantified in arbitrary units (AU) using ImageJ. D: Staining with proliferation marker Ki-67 (green) shows a statistically significant reduction in Ki-67 positivity in RK33treated cells compared with DMSO control (representative images for $\mathrm{BCaP}^{\mathrm{M} 1}$ are shown; images for $\mathrm{C} 42$ are not shown). DAPI nuclear stain is shown in blue. Percent positivity was calculated in ImageJ. E: Staining with apoptosis marker cleaved caspase (cCASP)-3 (red) does not show a statistically significant difference in positivity between RK33 and DMSO-treated cells (representative images for BCaP ${ }^{\mathrm{M} 1}$ are shown; images for C42 are not shown). DAPI nuclear stain is shown in blue. Percent positivity was calculated in ImageJ. $n=3$. ${ }^{*} P<0.05,{ }^{* *} P<0.01,{ }^{* * *} P<0.001$, and ${ }^{* * * *} P<0.0001$ versus RK33 treatment (Welch $t$-test). No significance reflects $P>0.05$. Scale bars $=50 \mu \mathrm{m}(\mathbf{C}-\mathbf{E})$.

$\mathrm{CaP}$ progression were used. First, DDX3 expression and localization was assessed in the $\mathrm{BCaP}$ model of $\mathrm{CaP}$ progression. ${ }^{40}$ The $\mathrm{BCaP}$ model was derived from the $\mathrm{BPH} 1$ cell line, which was immortalized from a nontumorigenic human prostate epithelial cell. ${ }^{41}$ When BPH1 tissue recombinants that contained rodent urogenital mesenchyme were grown in male athymic mice under steroid hormone treatment, epithelial cells in these grafts underwent malignant transformation as previously described. ${ }^{39,40,47}$ Cells isolated from tissue recombinants at different time points represent distinct stages of $\mathrm{CaP}$ progression: nontumorigenic $\left(\mathrm{BCaP}^{\mathrm{NT1}}\right)$, small indolent tumors $\left(\mathrm{BCaP}^{\mathrm{T} 1}\right)$, 
large aggressive tumors $\left(\mathrm{BCaP}^{\mathrm{T} 10}\right)$, and lymph node metastases $\left(\mathrm{BCaP}^{\mathrm{MT} 10}\right.$ and $\left.\mathrm{BCaP}^{\mathrm{M} 1}\right){ }^{39,40}$ In this model, DDX3 expression was significantly increased in both metastatic cell lines $\left(\mathrm{BCaP}^{\mathrm{MT} 10}, \mathrm{BCaP}^{\mathrm{M} 1}\right)$ compared with nontumorigenic line $\mathrm{BCaP}^{\mathrm{NT} 1}(P=0.038$ and $P=0.041$, respectively) (Figure 2A). Localization of DDX3 in $\mathrm{BCaP}$ cell lines found a DDX3 expression primarily in the cytoplasm (Figure 2B). In addition, these data confirmed the expression data from Figure 2A because DDX3 was more highly expressed in $\mathrm{BCaP}^{\mathrm{MT} 10}$ and $\mathrm{BCaP}^{\mathrm{M} 1}$ cell lines compared with cell lines representing earlier stages of carcinogenesis $\mathrm{BCaP}^{\mathrm{NT} 1}$ and $\mathrm{BCaP}^{\mathrm{T} 1}$.

DDX3 expression was analyzed in a panel of established $\mathrm{CaP}$ cell lines, including $\mathrm{LNCaP}$ and the advanced $\mathrm{LNCaP}$ derivatives $\mathrm{C} 42 \mathrm{~B}$ and $\mathrm{C} 42 .{ }^{48,49}$ Although $\mathrm{LNCaP}$ is lowly metastatic in vivo, its derivative, $\mathrm{C} 42$, is a model for metastatic $\mathrm{CaP}$ because it readily metastasizes in vivo. ${ }^{50} \mathrm{~A}$ significant increase was seen in DDX3 expression in the $\mathrm{CaP}$ cell lines DU145, C42B, and C42 compared with nontumorigenic cell lines RWPE-1 $(P=0.0027$, $P<0.0001$, and $P=0.0001$, respectively) (Figure 2C). Importantly, expression of DDX3 was significantly increased in advanced LNCaP derivative cell lines C42B and $\mathrm{C} 42$ compared with parental $\mathrm{LNCaP}(P=0.007$ and $P=0.0103$, respectively) (Figure 2C). Localization of DDX3 in LNCaP and C42 revealed DDX3 primarily in the cytoplasm (Figure 2D). Moreover, DDX3 was more robustly expressed in the advanced $\mathrm{LNCaP}$-derivative $\mathrm{C} 42$ versus parental $\mathrm{LNCaP}$ (Figure $2 \mathrm{C}$ and $\mathrm{D}$ ). These data provide evidence that $\mathrm{CaP}$ cell line models represent similar trends in DDX3 expression because patient data increased expression in advanced/metastatic $\mathrm{CaP}$ and localization to the cytoplasm. Therefore, these models are appropriate to investigate the role of DDX3 in the cytoplasm of metastatic $\mathrm{CaP}$.

\section{Genetic Knockdown of DDX3 Decreases Proliferation in CaP Metastasis Models}

To determine functional implications of DDX3 in the cytoplasm of $\mathrm{CaP}$ metastases, DDX3 was genetically knocked down in $\mathrm{BCaP}^{\mathrm{M} 1}$ and $\mathrm{C} 42$ cells. To ascertain the effect of DDX3 knockdown on general cell viability, cells were transiently transfected at day 0 with $25 \mathrm{nmol} / \mathrm{L}$ of either siDDX3 or siSCBL and counted using trypan blue at days 1,2 , and 4 after transfection. In $\mathrm{BCaP}^{\mathrm{M} 1}$, at days 1 and 2 , there was no significant change in cell number between siSCBL and siDDX3 transfected cells $(P=0.223$ and $P=0.085$, respectively). At day 4 , a statistically significant decrease of cell number in siDDX3-transfected cells was found compared with control $(P=0.021)$ (Figure 3A). In $\mathrm{C} 42$, no significant difference in cell number at day 1 was found $(P=0.081)$, but a significant decrease in cell number at days 2 and 4 in the DDX3 knockdown cells was found compared with control $(P=0.012$ and $P=0.035$, respectively) (Figure 3A). A significant reduction of DDX3 was found in siDDX3-transfected cells compared with control by immunoblot $\left[\mathrm{BCaP}^{\mathrm{M} 1}\right.$ fold change $(\mathrm{FC})=0.18$, $\mathrm{C} 42 \mathrm{FC}=0.3]$ and immunofluorescence $\left(\mathrm{BCaP}^{\mathrm{M} 1}\right.$ $P<0.0001, \mathrm{C} 42 P=0.0003)$, suggesting the siRNA was targeted and efficient (Figure 3, B-C). Similar to human $\mathrm{CaP}$ metastases, Figure 3C confirms DDX3 primarily in the cytoplasm of $\mathrm{BCaP}^{\mathrm{M} 1}$ cells, with similar results seen in $\mathrm{C} 42$ cells (images not shown). Two possible mechanisms through which DDX3 could decrease cell viability are slowing proliferation or inducing apoptosis. To differentiate between these two modalities, the expression of proliferation marker Ki-67 and apoptosis marker cCASP3 was quantified. A statistically significant reduction was seen in Ki-67 positivity in siDDX3-transfected cells compared with siSCBL $\left[\mathrm{BCaP}^{\mathrm{M} 1} P=0.007, \mathrm{C} 42\right.$ (images not shown), $P=0.021$ ] (Figure 3D). A change in cCASP3 staining between siSCBL and siDDX 3 cells was not seen $\left[\mathrm{BCaP}^{\mathrm{M} 1}\right.$ $P=0.341$, C42 (images not shown), $P=0.890$ ] (Figure 3E). Taken together, these data suggest that DDX3 plays a role in cell proliferation but not apoptosis in metastatic $\mathrm{CaP}$.

\section{Pharmacologic Inhibition of DDX3 Decreases Proliferation in CaP Metastasis Models}

Given that DDX3 genetic knockdown is sufficient to decrease proliferation in metastatic $\mathrm{CaP}$, it is possible that pharmacologic inhibition of DDX3 could produce similar results that are clinically relevant. RK33 is a small molecule inhibitor that specifically binds the ATP-binding domain of DDX3 and prevents its helicase activity. ${ }^{29}$ To determine the effect of DDX3 pharmacologic inhibition on cell viability, $\mathrm{BCaP}^{\mathrm{M} 1}$ and $\mathrm{C} 42$ cells were treated with $2 \mu \mathrm{M}$ RK33 or DMSO control at day 0. Cells were collected and counted using trypan blue at days 2, 4, and 6 afer treatment. At all time points assessed, there was a statistically significant decrease of cell number in $\mathrm{RK} 33$-treated $\mathrm{BCaP}^{\mathrm{M} 1}$ cells compared with DMSO control (day $2 P=0.004$, day 4 $P=0.031$, and day $6 P=0.005$ ) (Figure 4A). In C42, cell number was significantly decreased with RK33 treatment at days $4(P=0.0119)$ and $6(P=0.0355)$ (Figure $4 \mathrm{~A})$. Similar to genetic knockdown experiments, RK33-treated cells have lower expression of DDX3 protein by immunoblot $\left(\mathrm{BCaP}^{\mathrm{M} 1} \mathrm{FC}=0.38, \mathrm{C} 42 \mathrm{FC}=0.45\right)$ and immunofluorescence $\left[\mathrm{BCaP}^{\mathrm{M} 1} P=0.001, \mathrm{C} 42\right.$ (images not shown), $P=0.003$ ) (Figure $4, \mathrm{~B}$ and $\mathrm{C}$ ). To address the antiproliferative effect of DDX3 inhibition, Ki-67 expression was assessed and a significant reduction was seen in Ki-67 positivity in RK33-treated cells compared with control $\left[\mathrm{BCaP}^{\mathrm{M} 1} P=0.039, \mathrm{C} 42\right.$ (images not shown), $P=0.044$ ] (Figure 4D). There was no significant change in cCASP3 staining between RK33 and DMSO $\left[\mathrm{BCaP}^{\mathrm{M} 1} P=0.720\right.$, C42 (images not shown), $P=0.291$ ] (Figure 4E). Taken together, these data indicate that pharmacologic inhibition of DDX3 in metastatic $\mathrm{CaP}$ effectively decreases proliferation but does not induce apoptosis. 
Table 2 Cell Motility Decreases with DDX3 Inhibition

\begin{tabular}{|c|c|c|c|c|c|c|}
\hline \multirow{2}{*}{$\begin{array}{l}\text { Time, } \\
\text { hours }\end{array}$} & \multicolumn{6}{|l|}{$\mathrm{BCaP}^{\mathrm{M} 1}$} \\
\hline & DMSO & RK33 & $P$ value & SiSCBL & siDDX3 & $P$ value \\
\hline 6 & $14.01 \pm 2.15$ & $13.93 \pm 3.25$ & 0.986 & $17.04 \pm 4.58$ & $10.94 \pm 3.61$ & 0.357 \\
\hline 24 & $88.13 \pm 5.31$ & $43.18 \pm 3.71$ & 0.003 & $79.24 \pm 3.44$ & $56.29 \pm 3.33$ & $\begin{array}{c}\mathbf{0 . 0 0 9} \\
\text { (table continues) }\end{array}$ \\
\hline
\end{tabular}

Data are expressed as percentage of scratch closure \pm SEM. Bold values signify statistical significance between control and DDX3 inhibition at each time point. DMSO, dimethyl sulfoxide; siDDX3, siRNA targeting DDX3; siSCBL, siRNA nontargeting scramble control.

\section{Inhibition of DDX3 Decreases Cell Motility in Metastasis Models}

In addition to proliferation and apoptosis, the effect of genetic and pharmacologic DDX3 inhibition was assessed on cell motility (Table 2). A significant decrease was seen in the percentage of scratch closure with siDDX3 at 12 and 24 hours compared with scramble control for both $\mathrm{BCaP}^{\mathrm{M} 1}(12$ hours $P=0.013$; 24 hours $P=0.009$ ) and $\mathrm{C} 42$ (12 hours $P=0.042 ; 24$ hours $P=0.016$ ) (Table 2). No significant change in motility occurred between siDDX3 and siSCBL at 6 hours for either cell line $\left(\mathrm{BCaP}^{\mathrm{M} 1} P=0.357\right.$; $\mathrm{C} 42$ $P=0.445$ ) (Table 2). Similarly, there was a significant decrease in percentage of scratch closure with RK33 treatment at 12 and 24 hours compared with DMSO control for $\mathrm{BCaP}^{\mathrm{M} 1}$ (12 hours $P=0.025 ; 24$ hours $\left.P=0.003\right)$ and C42 (12 hours $P=0.02$; 24 hours $P=0.024$ ) (Table 2). There was no significant change in motility between RK33 and DMSO at 6 hours for either cell line $\left(\mathrm{BCaP}^{\mathrm{M} 1}\right.$ $P=0.986$; C42 $P=0.912$ ) (Table 2). Representative images for the motility assays are shown in Supplemental Figure S1. Taken together, these data suggest that genetic and pharmacologic inhibition of DDX3 is sufficient to decrease cell motility. These findings provide a foundation for potential clinical implications of targeting DDX3 in metastatic $\mathrm{CaP}$.

\section{Discussion}

Metastatic $\mathrm{CaP}$ remains a prevalent pathologic condition with low survival rates in part because of a dearth of knowledge about molecular changes associated with advanced disease. ${ }^{1}$ Thus, identifying and developing more effective targeted therapies for metastatic $\mathrm{CaP}$ are necessary to improve patient survival. DDX3 has been implicated in many cancer types as both a positive and negative prognostic marker. ${ }^{26}$ In primary $\mathrm{CaP}$, increased DDX3 is associated with $\mathrm{CaP}$ with a high Gleason score. ${ }^{27}$ Importantly, preclinical studies of RK33, a small molecule inhibitor specific to DDX3, have found a positive therapeutic value of targeting DDX3 in combination with radiotherapy in both lung and primary $\mathrm{CaP}^{27,29}$; however, DDX3 expression in $\mathrm{CaP}$ metastases had not been assessed before the current study. Here, although DDX3 expression was increased in some meta-analyses of $\mathrm{CaP}$ versus healthy samples, it was not significantly changed in others (Table 1). Importantly, there was a significant increase of DDX3 expression in a meta-analysis of metastatic versus primary $\mathrm{CaP}$ (Table 1 ), suggesting that increased DDX3 expression is associated with metastatic $\mathrm{CaP}$ and warranting further investigation of the function of DDX3 in this context.

As a helicase, DDX3 plays roles in both nuclear and cytoplasmic RNA processing. DDX3 acts as a translational regulator in the cytoplasm, whereas it contributes to mRNA transcription, splicing, and export in the nucleus; these established roles for DDX3 suggest that its localization provides insight into its function. To quantify DDX3 expression and localization in prostate tissue, an objective machine-learning approach with inForm software version 2.1 was used (Figure 1A). By assessing subcellular localization of DDX3 in progression, an increase of whole cell, nuclear, and cytoplasmic epithelial DDX3 expression was observed in primary CaP compared with BPT (Figure 1B), supporting previously published data. ${ }^{27}$ In metastatic $\mathrm{CaP}$, these data indicate that nuclear DDX3 was significantly decreased compared with primary $\mathrm{CaP}$ and similar to levels expressed in BPT. Interestingly, cytoplasmic DDX3 remained significantly increased in metastatic $\mathrm{CaP}$ compared with BPT (Figure 1B). These data suggest that cytoplasmic, not nuclear, DDX3 in the epithelial compartment is a characteristic of metastatic $\mathrm{CaP}$ and may have a functional significance in advanced disease. Alternatively, it is possible that the decrease in nuclear DDX3 is contributing to disease progression because loss of DDX3 is a negative prognostic marker in other cancer types, including lung, colon, and head and neck cancers. ${ }^{26}$ This finding may reveal an undescribed role for DDX3 in CaP progression, and future studies evaluating nuclear and cytoplasmic gain or loss of function may be informative.

To assess the loss of function of cytoplasmic DDX3 in metastatic CaP, DDX3 was inhibited in cell line models for metastatic $\mathrm{CaP}$ in two different ways: genetic knockdown with siRNA and pharmacologic inhibition with small molecule inhibitor RK33. These cell line models of $\mathrm{CaP}$ progression had similar trends for cytoplasmic DDX3 expression as metadata and clinical data, precipitating their use as models for assessing potential functional implications (Figure 2). With both genetic and pharmacologic loss of function, DDX3 expression was significantly decreased in 
Table 2 (continued)

\begin{tabular}{|c|c|c|c|c|c|}
\hline \multicolumn{6}{|l|}{ C42 } \\
\hline siSCBL & siDDX3 & $P$ value & DMSO & RK33 & $P$ value \\
\hline $14.43 \pm 5.63$ & $7.56 \pm 5.86$ & 0.445 & $14.72 \pm 2.27$ & $13.82 \pm 4.35$ & 0.912 \\
\hline $58.04 \pm 5.44$ & $29.4 \pm 3.89$ & 0.016 & $65.46 \pm 5.59$ & $36.62 \pm 2.07$ & 0.024 \\
\hline
\end{tabular}

metastatic CaP cells (Figures 3, B and C, and 4, B and C). Another study found a similar reduction of DDX3 protein after RK33 treatment, ${ }^{29}$ and Bol et al $^{26}$ suggested that the mechanism for this decrease in DDX3 protein occurs through DDX3 degradation. Significantly, genetic and pharmacologic inhibition was sufficient to decrease cell viability compared with control in two different models (Figures 3A and 4A). By staining with markers for proliferation or apoptosis, it was concluded that DDX3 may contribute to metastatic growth through proproliferative, not antiapoptotic, effects, because DDX3 loss of function resulted in decreased proliferation but no change in apoptosis (Figures 3, D and E, and 4, D and E). In addition, DDX3 inhibition decreased cell motility in both models (Table 2). Extrapolating from these key findings, we believe it is possible that targeting DDX3 therapeutically may slow metastasis or metastatic cell proliferation; because RK33 is well tolerated in preclinical models in vivo, this may be a useful strategy to prevent or treat metastatic growth. Moreover, inhibiting cytoplasmic DDX3 may affect the profile of translated mRNA because of its role as a translational regulator, and characterization of this metastatic translation profile may reveal additional targetable agents for metastatic CaP.

The implications for targeting DDX3 in CaP have only been assessed once previously and serve as the basis of our current understanding; nuclear DDX3 was highly expressed in primary $\mathrm{CaP}$ versus benign tissue, and combination treatment with RK33 and radiotherapy decreased proliferation and increased apoptosis. ${ }^{27}$ Here, we addressed DDX3 expression and localization in metastatic $\mathrm{CaP}$, differing from previous publication because of our focus on advanced stages of disease. ${ }^{27}$ This context is significant because of the low survival rates for men with metastatic CaP; RK33 is a nontoxic drug in vivo and if effective against metastatic $\mathrm{CaP}$ could be transitioned into the clinic quickly. DDX3 expression and localization in patient tissues were objectively quantified using a machine learning-based approach, implicating cytoplasmic, not nuclear, DDX3 in metastatic $\mathrm{CaP}$. This method is unique because it does not rely on traditional and subjective scoring methods, requiring less time for pathologists and decreasing interobserver variability to foster National Institutes of Health-mandated rigor and reproducibility. ${ }^{37}$ Finally, RK33 treatment alone was sufficient to decrease proliferation and motility but not induce apoptosis. In previous studies, RK33 treatment alone was not sufficient to affect proliferation or apoptosis in vitro or in vivo, and motility was not assessed. ${ }^{27,29}$ This discrepancy could be attributable to the difference in $\mathrm{CaP}$ models used in studies or the difference of DDX3 localization in models. To confirm results from previous publication, ${ }^{27}$ DU145 and PC3 cells were treated with RK33 alone, and a significant change in cell viability, proliferation, or apoptosis was not observed in vitro (data not shown). Although this study did not address combination treatments with RK33 (eg, radiotherapy), perhaps this therapeutic scheme would have even more significant effects than RK33 alone in metastatic $\mathrm{CaP}$ and should be explored in future studies.

In summary, cytoplasmic DDX3 is highly expressed in metastatic $\mathrm{CaP}$, and inhibiting DDX3 in this context genetically and pharmacologically was sufficient to attenuate proliferation and motility. These analyses i) provide insight into expression and localization changes related to metastasis, ii) implicate cytoplasmic DDX3 as a feature of metastatic $\mathrm{CaP}$, iii) introduce a previously undescribed role of cytoplasmic DDX3 in $\mathrm{CaP}$ progression, and iv) provide a foundation for potential clinical implications of targeting DDX3 in metastatic CaP. Consequently, further investigation into the role of cytoplasmic DDX3 in metastatic CaP may elucidate mechanisms underlying progression to advanced disease that result in reduced patient survival.

\section{Acknowledgments}

We thank the University of Wisconsin Translational Research Initiatives in Pathology Laboratory for use of its facilities and services; Dr. Glen Leverson for assistance with statistical analysis; and Drs. Teresa Liu, Samuel Thomas, Dalton McLean, Kristen Uchtmann, and Christian OrtizHernandez for manuscript editing.

\section{Supplemental Data}

Supplemental material for this article can be found at https://doi.org/10.1016/j.ajpath.2019.02.011. 


\section{References}

1. Siegel RL, Miller KD, Jemal A: Cancer statistics, 2017. CA Cancer J Clin 2017, 67:7-30

2. Kirby M, Hirst C, Crawford E: Characterising the castration-resistant prostate cancer population: a systematic review. Int Journal Clin Pract 2011, 65:1180-1192

3. Sumanasuriya S, De Bono J: Treatment of advanced prostate cancer-A review of current therapies and future promise. Cold Spring Harb Perspect Med 2018, 8:a030635

4. Petrylak DP, Tangen CM, Hussain MH, Lara PN Jr, Jones JA, Taplin ME, Burch PA, Berry D, Moinpour C, Kohli M: Docetaxel and estramustine compared with mitoxantrone and prednisone for advanced refractory prostate cancer. N Engl J Med 2004, 351:1513-1520

5. Berthold DR, Pond GR, Soban F, de Wit R, Eisenberger M, Tannock IF: Docetaxel plus prednisone or mitoxantrone plus prednisone for advanced prostate cancer: updated survival in the TAX 327 study. J Clin Oncol 2008, 26:242-245

6. Small EJ, Schellhammer PF, Higano CS, Redfern CH, Nemunaitis JJ, Valone FH, Verjee SS, Jones LA, Hershberg RM: Placebo-controlled phase III trial of immunologic therapy with sipuleucel-T (APC8015) in patients with metastatic, asymptomatic hormone refractory prostate cancer. J Clin Oncol 2006, 24:3089-3094

7. Higano CS, Schellhammer PF, Small EJ, Burch PA, Nemunaitis J, Yuh L, Provost N, Frohlich MW: Integrated data from 2 randomized, double-blind, placebo-controlled, phase 3 trials of active cellular immunotherapy with sipuleucel-T in advanced prostate cancer. Cancer 2009, 115:3670-3679

8. Botlagunta M, Vesuna F, Mironchik Y, Raman A, Lisok A, Winnard P Jr, Mukadam S, Van Diest P, Chen J, Farabaugh P: Oncogenic role of DDX3 in breast cancer biogenesis. Oncogene 2008, 27:3912

9. Chao C-H, Chen C-M, Cheng P-L, Shih J-W, Tsou A-P, Lee Y-HW: DDX3, a DEAD box RNA helicase with tumor growth-suppressive property and transcriptional regulation activity of the $\mathrm{p} 21 \mathrm{waf} 1 / \mathrm{cip} 1$ promoter, is a candidate tumor suppressor. Cancer Res 2006, 66: $6579-6588$

10. Soulat D, Bürckstümmer T, Westermayer S, Goncalves A, Bauch A, Stefanovic A, Hantschel O, Bennett KL, Decker T, Superti-Furga G: The DEAD-box helicase DDX3X is a critical component of the TANK-binding kinase 1-dependent innate immune response. EMBO J 2008, 27:2135-2146

11. van Voss MRH, Schrijver WA, Ter Hoeve ND, Hoefnagel LD, Manson QF, van der Wall E, Raman V, van Diest PJ; Dutch Distant Breast Cancer Metastases Consortium: The prognostic effect of DDX3 upregulation in distant breast cancer metastases. Clin Exp Metastasis 2017, 34:85-92

12. Wu D-W, Lin P-L, Cheng Y-W, Huang C-C, Wang L, Lee H: DDX3 enhances oncogenic KRAS-induced tumor invasion in colorectal cancer via the $\beta$-catenin/ZEB1 axis. Oncotarget 2016, 7:22687

13. Wu D, Lee M, Wang J, Chen C, Cheng Y, Lee H: DDX3 loss by p53 inactivation promotes tumor malignancy via the MDM2/Slug/Ecadherin pathway and poor patient outcome in non-small-cell lung cancer. Oncogene 2014, 33:1515

14. Merz C, Urlaub H, Will CL, Lührmann R: Protein composition of human mRNPs spliced in vitro and differential requirements for mRNP protein recruitment. Rna 2007, 13:116-128

15. Zhou Z, Licklider LJ, Gygi SP, Reed R: Comprehensive proteomic analysis of the human spliceosome. Nature 2002, 419:182

16. Lai M-C, Lee Y-HW, Tarn W-Y: The DEAD-box RNA helicase DDX3 associates with export messenger ribonucleoproteins as well astip-associated protein and participates in translational control. Mol Biol Cell 2008, 19:3847-3858

17. Yedavalli VS, Neuveut C, Chi Y-H, Kleiman L, Jeang K-T: Requirement of DDX3 DEAD box RNA helicase for HIV-1 RevRRE export function. Cell 2004, 119:381-392
18. Lee C-S, Dias AP, Jedrychowski M, Patel AH, Hsu JL, Reed R: Human DDX3 functions in translation and interacts with the translation initiation factor eIF3. Nucleic Acids Res 2008, 36:4708-4718

19. Shih J-W, Wang W-T, Tsai T-Y, Kuo C-Y, Li H-K, Lee Y-HW: Critical roles of RNA helicase DDX3 and its interactions with eIF4E/PABP1 in stress granule assembly and stress response. Biochem J 2012, 441:119-129

20. Soto-Rifo R, Rubilar PS, Limousin T, De Breyne S, Decimo D, Ohlmann T: DEAD-box protein DDX3 associates with eIF4F to promote translation of selected mRNAs. EMBO J 2012, 31: $3745-3756$

21. Oh S, Flynn RA, Floor SN, Purzner J, Martin L, Do BT, Schubert S, Vaka D, Morrissy S, Li Y: Medulloblastoma-associated DDX3 variant selectively alters the translational response to stress. Oncotarget 2016, 7:28169

22. Anderson P, Kedersha N: Stressful initiations. J Cell Sci 2002, 115: $3227-3234$

23. Buchan JR, Parker R: Eukaryotic stress granules: the ins and outs of translation. Mol Cell 2009, 36:932-941

24. Chen H, Yu H, Cho W, Tarn W: DDX3 modulates cell adhesion and motility and cancer cell metastasis via Rac1-mediated signaling pathway. Oncogene 2015, 34:2790

25. Lai M-C, Chang W-C, Shieh S-Y, Tarn W-Y: DDX3 regulates cell growth through translational control of cyclin E1. Mol Cell Biol 2010, 30:5444-5453

26. Bol GM, Xie M, Raman V: DDX3, a potential target for cancer treatment. Mol Cancer 2015, 14:188

27. Xie M, Vesuna F, Tantravedi S, Bol GM, Van Voss MRH, Nugent K, Malek R, Gabrielson KL, Van Diest PJ, Tran PT: RK-33 radiosensitizes prostate cancer cells by blocking the RNA helicase DDX3 . Cancer Res 2016, 76:6340-6350

28. Epstein JI, Allsbrook WC Jr, Amin MB, Egevad LL, Committee IG: The 2005 International Society of Urological Pathology (ISUP) consensus conference on Gleason grading of prostatic carcinoma. Am J Surg Pathol 2005, 29:1228-1242

29. Bol GM, Vesuna F, Xie M, Zeng J, Aziz K, Gandhi N, Levine A, Irving A, Korz D, Tantravedi S: Targeting DDX3 with a small molecule inhibitor for lung cancer therapy. EMBO Mol Med 2015, 7: 648-669

30. Rhodes DR, Yu J, Shanker K, Deshpande N, Varambally R, Ghosh D, Barrette T, Pander A, Chinnaiyan AM: ONCOMINE: a cancer microarray database and integrated data-mining platform. Neoplasia 2004, 6:1-6

31. Wallace TA, Prueitt RL, Yi M, Howe TM, Gillespie JW, Yfantis HG, Stephens RM, Caporaso NE, Loffredo CA, Ambs S: Tumor immunobiological differences in prostate cancer between AfricanAmerican and European-American men. Cancer Res 2008, 68: 927-936

32. Grasso CS, Wu Y-M, Robinson DR, Cao X, Dhanasekaran SM, Khan AP, Quist MJ, Jing X, Lonigro RJ, Brenner JC: The mutational landscape of lethal castration-resistant prostate cancer. Nature 2012, 487:239

33. Tomlins SA, Mehra R, Rhodes DR, Cao X, Wang L, Dhanasekaran SM, Kalyana-Sundaram S, Wei JT, Rubin MA, Pienta KJ: Integrative molecular concept modeling of prostate cancer progression. Nat Genet 2007, 39:41

34. Singh D, Febbo PG, Ross K, Jackson DG, Manola J, Ladd C, Tamayo P, Renshaw AA, D’Amico AV, Richie JP: Gene expression correlates of clinical prostate cancer behavior. Cancer Cell 2002, 1: 203-209

35. LaTulippe E, Satagopan J, Smith A, Scher H, Scardino P, Reuter V, Gerald WL: Comprehensive gene expression analysis of prostate cancer reveals distinct transcriptional programs associated with metastatic disease. Cancer Res 2002, 62:4499-4506

36. Varambally S, Yu J, Laxman B, Rhodes DR, Mehra R, Tomlins SA, Shah RB, Chandran U, Monzon FA, Becich MJ: Integrative genomic 
and proteomic analysis of prostate cancer reveals signatures of metastatic progression. Cancer Cell 2005, 8:393-406

37. Huang W, Hennrick K, Drew S: A colorful future of quantitative pathology: validation of Vectra technology using chromogenic multiplexed immunohistochemistry and prostate tissue microarrays. Hum Pathol 2013, 44:29-38

38. Bauman TM, Vezina CM, Ricke EA, Halberg RB, Huang W, Peterson RE, Ricke WA: Expression and colocalization of $\beta$-catenin and lymphoid enhancing factor-1 in prostate cancer progression. Hum Pathol 2016, 51:124-133

39. Hayward SW, Wang Y, Cao M, Hom YK, Zhang B, Grossfeld GD, Sudilovsky D, Cunha GR: Malignant transformation in a nontumorigenic human prostatic epithelial cell line. Cancer Res 2001, 61:8135-8142

40. Liu TT, Ewald JA, Ricke EA, Bell R, Collins C, Ricke WA: Modeling human prostate cancer progression in vitro. Carcinogenesis 2018:bgy 185

41. Hayward S, Dahiya R, Cunha G, Bartek J, Deshpande N, Narayan P: Establishment and characterization of an immortalized but nontransformed human prostate epithelial cell line: BPH-1. In Vitro Cell Dev Biol Anim 1995, 31:14-24

42. Towbin H, Staehelin T, Gordon J: Electrophoretic transfer of proteins from polyacrylamide gels to nitrocellulose sheets: procedure and some applications. Proc Natl Acad Sci U S A 1979, 76:4350-4354

43. Colella AD, Chegenii N, Tea MN, Gibbins IL, Williams KA, Chataway TK: Comparison of Stain-Free gels with traditional immunoblot loading control methodology. Anal Biochem 2012, 430: $108-110$

44. Schneider CA, Rasband WS, Eliceiri KW: NIH Image to ImageJ: 25 years of image analysis. Nat Methods 2012, 9:671

45. Levenson R: Putting the "more" back in morphology: spectral imaging and image analysis in the service of pathology. Arch Pathol Lab Med 2008, 132:748-757

46. Mansfield JR: Cellular context in epigenetics: quantitative multicolor imaging and automated per-cell analysis of miRNAs and their putative targets. Methods 2010, 52:271-280

47. Ricke WA, Ishii K, Ricke EA, Simko J, Wang Y, Hayward SW, Cunha GR: Steroid hormones stimulate human prostate cancer progression and metastasis. Int J Cancer 2006, 118:2123-2131

48. Thalmann GN, Anezinis PE, Chang S-M, Zhau HE, Kim EE, Hopwood VL, Pathak S, von Eschenbach AC, Chung LW: Androgen-independent cancer progression and bone metastasis in the LNCaP model of human prostate cancer. Cancer Res 1994, 54: 2577-2581

49. McLean DT, Strand DW, Ricke WA: Prostate cancer xenografts and hormone induced prostate carcinogenesis. Differentiation 2017, 97: $23-32$

50. Sato N, Gleave ME, Bruchovsky N, Rennie PS, Beraldi E, Sullivan LD: A metastatic and androgen-sensitive human prostate cancer model using intraprostatic inoculation of LNCaP cells in SCID mice. Cancer Res 1997, 57:1584-1589 